\title{
MoP.102
}

\section{Structural order of thin film silicon made at $100{ }^{\circ} \mathrm{C}$}

\author{
J.K. Rath ${ }^{1}$, R.E.I. Schropp ${ }^{1}$, and P. Roca i Cabarrocas ${ }^{2}$ \\ ${ }^{1}$ Utrecht University, Faculty of Science, SID - Physics of Devices, P.O. Box 80,000, 3508 TA Utrecht, Netherlands \\ ${ }^{2}$ LPICM, Ecole Polytechnique, CNRS, -91128 Palaiseau France
}

Thin film silicon solar cells that could be used as power supplies for devices on plastic, need to be processed at a low temperature of $\leq 100{ }^{\circ} \mathrm{C}$ (which is compatible for most of the plastics such as PEN, PES and many types of PET). However, deposition of amorphous silicon (a-Si:H) by a CVD process at temperatures lower than $200{ }^{\circ} \mathrm{C}$ usually leads to increased structural disorder and defects in the material, owing to a lowering of the diffusion length of precursors on the growing surface. By optimizing hydrogen to silane flow ratio for the deposition of the i-layer, we have been able to make solar cells at $100{ }^{\circ} \mathrm{C}$ on Asahi TCO substrates in the p-i-n configuration with efficiencies of $7.8 \%$ by very high frequency plasma enhanced chemical vapour deposition (VHF PECVD) and $3.4 \%$ by hot-wire chemical vapour deposition (HWCVD). The purpose of this paper is to study the structural order of optimal materials at low deposition temperature for solar cell applications.

The dielectric functions obtained by spectroscopic ellipsometry (SE) of the thin film silicon materials on glass have been simulated by using the Tauc-Lorentz (TL) dispersion law [1]. The imaginary part of the dielectric function in a TL model is described by, $\varepsilon_{i m}(E)=\frac{A \cdot E_{0} \cdot C \cdot\left(E-E_{g}\right)^{2}}{\left(E^{2}-E_{g}\right)^{2}+C^{2} \cdot E^{2}} \frac{1}{E}$ for $E>E_{g}$ and $E_{i m}(E)=0$ for $E \leq E_{g}$, where $E_{0}$ is the peak transition energy, $E_{g}$ is the gap energy, $C$ is a broadening parameter, which is related to the disorder in the material and A is related to the film denseness [1]. We have fitted the dielectric function of three types of amorphous silicon samples, made at $100{ }^{\circ} \mathrm{C}$ by (i) HWCVD (ii) VHF-PECVD and (iii) standard PECVD $(13.56 \mathrm{MHz})$, and two a-Si:H samples made at $200{ }^{\circ} \mathrm{C}$ as reference. The SE data are analysed taking into account the substrate, the thin film bulk and its surface roughness, which is considered as an overlayer formed by a mixture consisting of $50 \%$ bulk material and $50 \%$ voids

The Table (given below) shows the fitting parameters of the ellipsometry data. As a reference, the $C$ and $A$ parameters of our device quality PECVD sample deposited at $200{ }^{\circ} \mathrm{C}$ are well comparable to literature values [1] and significantly smaller than that of $100{ }^{\circ} \mathrm{C}$ PECVD samples, confirming the effect of substrate temperature on the structural order. However, the VHF sample made at $100{ }^{\circ} \mathrm{C}$ using an optimum $\mathrm{H}_{2}$ dilution shows denseness (A value) and structural order $\left(C\right.$ value) that are comparable to the sample made at $200{ }^{\circ} \mathrm{C}$. The HWCVD materials in general have a less dense structure and higher roughness compared to the plasma deposited samples. This can be attributed to the absence of ion impact on the growing film. However, the A parameter of HWCVD samples is continuously improved with increasing dilution. Among all samples considered, it is observed that the $\mathrm{C}$ parameter reaches the lowest value $(C=1.67)$ for the HWCVD sample made at an optimum $\mathrm{R}$ value of 20 , even though it was made only at $100{ }^{\circ} \mathrm{C}$. The Raman spectra of these samples also confirm this high structural order [2]. This material also shows the best device quality with a photoresponse of $>10^{5}$.

\begin{tabular}{lllllllll}
\hline Process & $\mathrm{T}\left({ }^{\circ} \mathrm{C}\right)$ & $\mathrm{R}=\mathrm{H}_{2} / \mathrm{SiH}_{4}$ & $\begin{array}{l}\text { Roughness } \\
(\mathrm{nm})\end{array}$ & $E_{g}(\mathrm{eV})$ & $\mathrm{A}$ & $E_{0}(\mathrm{eV})$ & $\mathrm{C}$ & $\begin{array}{l}\text { Solar cell } \\
\text { Eff. }(\%)\end{array}$ \\
\hline PECVD $(1)$ & 100 & Pure Silane & & 1.65 & 201 & 3.66 & 2.39 & \\
PECVD & 100 & Pure Silane & 4.9 & 1.74 & 194 & 3.69 & 2.38 & \\
VHF & 100 & 20 & 4.7 & 172 & 206 & 3.62 & 2.10 & 7.8 \\
HWCVD & 100 & 7.5 & 14.4 & 1.85 & 154 & 3.77 & 2.25 & \\
HWCVD & 100 & 10 & 13.2 & 1.78 & 182 & 3.62 & 1.67 & 3.4 \\
HWCVD & 100 & 30 & 8.8 & 1.83 & 214 & 3.68 & 2.08 & \\
VHF & 200 & 1 & 10.5 & 1.72 & 216 & 3.42 & 2.02 & \\
PECVD & 200 & Pure Silane & 4.3 & 1.64 & 209 & 3.62 & 2.27 & \\
PECVD $(1)$ & 200 & Pure Silane & & 1.66 & 216 & 3.62 & 2.29 & \\
\hline
\end{tabular}

\section{References}

1. A. Fontcuberta i Morral, P. Roca i Cabarrocas, C. Clerc, Phys. Rev. B, 69, 125307 (2004).

2. J.K.Rath et al., Conf. Record of 2006 IEEE 4th WCPEC, Hawaii, 1544 (2006). 